\title{
A Lines-of-Defense Model for Managing Health Threats: A Review
}

\author{
Jutta Heckhausen ${ }^{\mathrm{a}}$ Carsten Wrosch $^{c}$ Richard Schulz ${ }^{\mathrm{b}}$

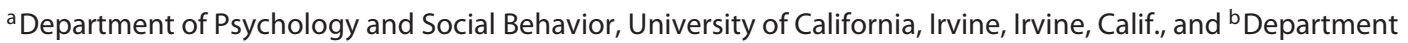 \\ of Psychiatry and University Center for Social and Urban Research, University of Pittsburgh, Pittsburgh, Pa., USA; \\ 'Department of Psychology, Concordia University, Montreal, Que., Canada
}

\section{Key Words \\ Control striving · Lines-of-Defense Model · Motivational Theory of Life-Span Development · Physical decline}

\begin{abstract}
As older individuals face challenges of progressive disease and increasing disability and approach the end of their lives, their capacity for controlling their environment and own health and functioning declines. The Lines-of-Defense Model is based on the Motivational Theory of Life-Span Development and proposes that individuals can adjust their control striving to the progressive physical decline in distinctly organized cycles of goal engagement and goal disengagement that reflect sequentially organized lines of defense. This organized process allows individuals to hold onto and defend still feasible levels of physical health and functioning in activities of daily living, while adjusting to increasing impairments. As physical constraints become more severe towards the end of life, avoiding psychological suffering becomes the focus of individuals' strivings for control. The Lines-ofDefense Model can also be applied to the inverse process of growth in functioning during recovery and rehabilitation.
\end{abstract}

Copyright $\odot 2013$ S. Karger AG, Basel

Late in life many individuals face considerable loss of control over everyday functioning due to failing health and disability [1]. The major regulatory challenge for old- er adults with health problems and progressive disability is to avoid futile battles while maintaining as much functional capacity as possible. In this article we propose the Lines-of-Defense Model, which is a domain-specific application of the Motivational Theory of Life-Span Development (MLD) [2-4]. We discuss the theory and its action-phase model of developmental regulation first and then apply it to the management of health and disability in older adulthood. We propose, in a nutshell, that individuals experiencing progressive decline in functioning should organize their behavior and control strivings in such a way that at any given time they know which functional capacities and activities to defend and which to let go. We identify specific lines of defense and their implications for use of control strategies, health-related goals, and functioning.

\section{The MLD and Its Propositions}

Our MLD focuses on the impressive adaptive capacity of individuals to optimize their development across major changes in control capacity during their life span. This

Preparation of this manuscript was in part supported by grants from the Canadian Institutes of Health Research and Social Sciences and Humanities Research Council of Canada to the second author and from the National Institute on Aging (AG026010, AG032370), National Institute for Nursing Research (NR009573) and the National Institute of Mental Health (MH071944) to the third author.

\section{KARGER}

E-Mail karger@karger.com www.karger.com/ger
(C) 2013 S. Karger AG, Basel

0304-324X/13/0595-0438\$38.00/0
Jutta Heckhausen, $\mathrm{PhD}$

Department of Psychology and Social Behavior

University of California, Irvine

Irvine, CA 92697-7085 (USA)

E-Mail heckhaus@uci.edu 
emphasis on adaptive developmental regulation is shared with other theoretical frameworks [5, 6] (for a thorough conceptual comparison of these approaches, see $[7,8]$ ). It assumes that the adaptive capacity of the individual depends on the regulation of motivation. Potential gains in functioning during periods of ample opportunities cannot be realized without motivationally engaging with relevant goals. Likewise, unavoidable losses in functioning and control capacity would expose individuals to overwhelming frustration and despair if they were not able to disengage from futile goals, protect their sense of personal control, and reengage with feasible alternative goals.

The MLD proposes that the key criterion for adaptive development is the extent to which the individual realizes primary control capacity of her/his environment across multiple domains of life and across the life span. Conditions change during the course of life: an individual's capacity for primary control rapidly increases during childhood and adolescence, grows and plateaus in midlife, and declines during old age. The critical challenge for the individual is to adapt to these changes by choosing the appropriate goals to engage with and giving up goals that have become or are unattainable. Thus, goals chosen for motivational investment should reflect the individual's actual opportunities for control and not just be pie-inthe-sky desiderata - we refer to this process as 'the congruence principle'. Extensive evidence supports this proposition by showing that congruence between control opportunities and goal selection has beneficial consequences both for subjective well-being and objective developmental outcomes [3].

Once a developmental goal is chosen, a specific set of control strategies that together facilitate 'goal engagement' is activated. This set of control strategies includes, for example, investment of time, effort, skill resources (i.e. selective primary control), and committing to the selected goal by enhancing its perceived value (i.e. selective secondary control). In addition, an individual who lacks critical skills or other resources may facilitate goal engagement by using additional means or assistance from others (i.e. compensatory primary control).

In contrast, specific control strategies of 'goal disengagement' are activated when a goal turns out to be unattainable (i.e. compensatory secondary control). These strategies serve to deactivate the motivational commitment to unattainable goals and to protect motivational resources for future control striving (e.g. protecting selfesteem or maintaining an optimistic outlook) by focusing, for example, on success in other domains or comparing one's performance with less effective others.

Lines-of-Defense Model for Managing Health Threats

\section{Action-Phase Model of Developmental Regulation}

The MLD further proposes that the pursuit of developmental goals can unfold over extended periods of time and is organized in sequential cycles of goal choice, goal engagement, and goal disengagement. This model of developmental regulation is based on a general action-phase model that focuses on the sequence of goal selection and goal engagement, sometimes referred to as the Rubicon Model of Action Phases [9]. Our model expands the Rubicon model in two ways: we include the 'developmental deadline', a transition between goal engagement and disengagement when opportunities have become depleted, and we propose an urgency phase of goal engagement just before a developmental deadline is reached. Figure 1 shows how an action cycle unfolds across the phases of choosing a goal, engaging motivationally and behaviorally with it, encountering depleted opportunities for goal attainment, and disengaging from the goal when it is no longer attainable.

During the first phase of optimized goal choice, individuals use three general heuristics. First, they choose goals that are congruent with their control capacity. Second, they select those goals that minimize unfavorable, and maximize favorable, consequences for other domains of functioning. And third, individuals try to maintain some cross-goal diversity in their goal pursuits to maintain developmental options in case of failure. Once the individual has made a decision about which goal to pursue (and thus crossed the decisional Rubicon), she/he moves into the phase of goal engagement. An important aspect of this phase is that perceptions and information processing become biased toward the goal being pursued [9]. For example, when women are engaged with the goal of bearing a child, their information processing (e.g. what they recall in an incidental memory task) is attuned to child-relevant topics [10]. For many goal pursuits the opportunities vary over time and across age, and can be characterized by an inverted U-shaped trajectory of agegraded changes from increase to peak to decrease. As opportunities (e.g. child-bearing or career advancement) fade away, the pursuit of these goals becomes increasingly urgent and thus individuals need to intensify their goal engagement efforts. As opportunities for goal attainment decline, the individual is confronted with increasing difficulty and having to invest more resources to still attain the goal. During the transition of passing a developmental deadline, this experience may give rise to a reevaluation of the goal and finally, once the opportunities for goal attainment have slipped away so much that further at- 
Fig. 1. Action-phase model of developmental regulation (adapted from Heckhausen, 1999).

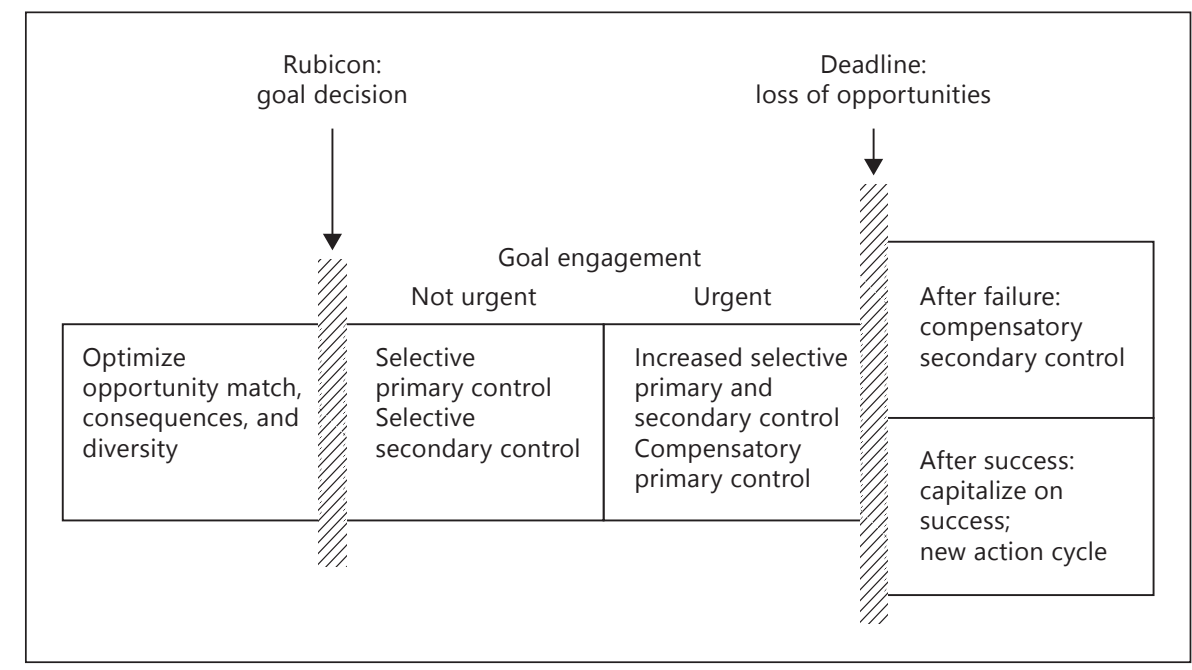

tempts are futile, individuals need to switch from goal engagement to goal disengagement.

An important proposition of the action-phase model is that the shifts from goal choice to goal engagement and from goal engagement to goal disengagement are not gradual, but discrete und radical. Behavior and thoughts should not oscillate between engagement and disengagement, but be coordinated with regard to the given function of the action phase (goal choice, goal engagement, or goal disengagement). This idea of radical and discrete switching between action phases has not yet been addressed in empirical research. Nonetheless, some theoretical frameworks have suggested that failure experiences and associated negative affect can prompt the individual to step out of the volitional commitment of goal engagement, reevaluate a situation, and decide whether a goal should be further pursued or abandoned (e.g. control theory [11]). However, others have argued that automatic and nonconscious processes may underlie a shift from goal engagement to disengagement [12]. Both, deliberative and automatic goal disengagement processes may be adaptive in a wide variety to situations. Nonconscious and automatic reduction of commitment from goals could be particularly useful if a certain unfeasible goal is of high priority or centrality for an individual's functioning or identity, and intentional disengagement is therefore ineffective.

Note that there is considerable variability in an individual's ability to negotiate important life transitions. As a consequence, different individuals attain different longterm outcomes of developmental regulation, both subjectively and objectively [3]. Those who have major difficul- ties with choosing appropriate goals, engaging in attainable goals, or disengaging from unattainable goals, waste their control efforts and deplete their resources for future primary control striving. On the other hand, those who manage these transitions in accordance with their capacity for control maximize their developmental potential and the likelihood of successful life-span development.

\section{Can the Action-Phase Model Be Applied to the Health Domain?}

The key propositions of the MLD make this theory particularly suitable for addressing adaptive processes to emerging health threats among older adults. Chronic illness and functional disability pose significant challenges to the motivational system of control striving because they endanger an individual's most fundamental of resources needed for primary control striving, physical integrity and fitness [13]. In fact, the maintenance of physical health has been identified as a first-order criterion for successful aging and optimizing primary control capacity [4]. This notion of hierarchically organized levels of functioning can be applied to processes of progressive disability, and indeed also the inverse, processes of rehabilitation. Accordingly, the individual's healthrelated goals can be conceptualized with respect to three hierarchically organized tasks (table 1, column 'Health goal'): (1) to improve functioning from a given level to the next better level, (2) to maintain (defend) functioning on a given level, and (3) to slow down decline from one level to the next lower level. 
Table 1. The Lines-of-Defense Model for motivational regulation with a progressive disease

\begin{tabular}{|c|c|c|c|}
\hline Disease state & Health goal & Functioning goal & Control strategy \\
\hline 1. Disease free & $\begin{array}{l}\text { a enhance resilience to disease by } \\
\text { preventive health behavior } \\
\text { b maintain disease-free status }\end{array}$ & & engagement \\
\hline 2. Subclinical disease & $\begin{array}{l}\text { a revert to disease-free state } \\
\text { b maintain status quo } \\
\text { c minimize progression }\end{array}$ & & $\begin{array}{l}\text { engagement } \rightarrow \\
\text { disengagement } \rightarrow \\
\text { reengagement }\end{array}$ \\
\hline 3. Chronic disease & $\begin{array}{l}\text { a revert to subclinical or } \\
\text { disease-free state } \\
\text { b avoid disease progression }\end{array}$ & $\begin{array}{l}\text { a regain or maintain lost physical } \\
\text { abilities } \\
\text { b maintain independence using } \\
\text { assistive devices and environmental } \\
\text { modifications } \\
\text { c seek and accept help from others } \\
\text { d focus on important I/ADL } \\
\text { e minimize physical suffering }\end{array}$ & $\begin{array}{l}\text { at each sublevel: cycles of } \\
\text { engagement } \rightarrow \\
\text { disengagement } \rightarrow \\
\text { reengagement }\end{array}$ \\
\hline
\end{tabular}

Extant theory and research has emphasized the importance of motivational processes for dealing with physical health problems, either from an action-phase perspective or by distinguishing potentially manageable from progressively declining chronic disease [14, 15]. Different from these approaches, we argue here that adaptive control striving for important health goals is organized in cycles of goal engagement and disengagement with progressively organized 'lines of defense' [16]. In particular, we suggest that adaptive regulation of health constraints requires individuals to shift from goal engagement to an organized retreat behind the next line of defense if goal attainment becomes unfeasible. For example, when suffering gradually declining eye sight with macular degeneration and having exhausted effective medical treatments, an adaptive strategy of organized retreat would be to disengage from trying to find a medical cure and instead pursuing the goal of reorganizing the home environment so as to enable oneself to continue with everyday activities in spite of worsening visual capacity (see also [17]). As individuals strive to maintain as much primary control capacity as possible under the conditions of illness and/or aging-related physical decline, they have to face constantly advancing constraints on controllability. Thus, over time the individual needs to adjust her/his health-related goals step-by-step to the progression of the disease and the associated functional disability.

Lines-of-Defense Model for Managing Health Threats

\section{Challenges of Disease and Disability in Mid- and Late Life}

Chronic disease is rare among young adults, but becomes quite prominent in midlife and common in late life [1]. In late midlife and early old age, people with chronic conditions often experience more manifest symptoms that begin to compromise physical functioning and everyday activities $[1,18]$. Nonfatal chronic conditions such as arthritis, chronic back conditions, high blood pressure, and visual and hearing impairments are common at this stage in the life span. Over time, these conditions have functional consequences that limit an individual's ability to carry out activities of daily living (ADL). Thus, individuals and their families have to master the challenges of chronic and progressive declines in functioning and increasingly severe and multifaceted symptoms.

The progression from chronic disease and its pathology to impairments, functional limitations, and eventually disability has been well documented and described elsewhere $[18,19]$. We argue that this process can be associated with significant activity restrictions, loss of independence, and suffering, which require the individual to engage in organized cycles of control strategies to prevent further decline and maintain quality of life. 


\section{Activity Restriction}

The MLD proposes that restrictions or losses to primary control capacity are a major threat to an individual's motivational functioning and elicit negative emotional responses and intense striving to regain primary control capacity [2-4]. Indeed, research on responses to major life stressors has revealed that one of the major determinants of a stressor's effects on psychological adjustment is the extent to which it restricts an individual's normal day-to-day activities (i.e. ADL and instrumental (I) ADL [20], also see the Activity Restriction Model of Depressed Affect [21-23]).

\section{Loss of Independence}

Functional disability can become severe and render an older adult dependent on the help and care of others. This process may start with requiring help for out-of-thehome activities, such as traveling or shopping. Further along the progression of the disease, more basic ADL may be affected, such as cooking meals and getting dressed. Many people find these dependencies deeply troubling because they imply a loss of autonomy and dignity, feeling indebted to others, and experiencing guilt about burdening one's loved ones. These consequences may occur particularly among individuals who pose a high value and importance on independence. For example, Martire et al. [24] found among osteoarthritis patients that self-efficacy in managing pain was positively affected by spousal support only among those who did not see independence from others as central to their identity. By contrast, depressive symptoms and slower walk time were associated with spousal support among those who placed greater personal importance on independence from others.

However, dependency on other people's help is not an all-or-nothing matter. Older and/or disabled adults may need help with some activities, but manage to maintain their independence in others. In this regard, allowing others to help with burdensome activities may protect resources needed for other more cherished endeavors. This idea is at the heart of Margaret Baltes' [25] notion of 'self-induced dependency' as an adaptive strategy that is focused on independence regarding select and personally important activities at the expense of relinquishing independence and accepting help for other activities that are less personally meaningful (table 1, transition from $3 \mathrm{c}$ to $3 \mathrm{~d}$ ).

\section{Suffering}

Besides activity restrictions and threats to personal independence, there are often physical symptoms that occur during the disablement process. These symptoms may become too severe to be ameliorated through goal disengagement or self-protection. Such intense physical symptoms have been summarized in research on 'physical suffering' and include pain, shortness of breath, and nausea among others [3]. Due to their experiential salience, these symptoms call for primary control attempts to avoid or at least ameliorate them (e.g. pain medication).

In addition to physical symptoms, patients may struggle with 'psychological suffering', for example when they feel they are a burden to others, experience depression, anxiety, loneliness, or guilt. Finally, particularly at the end of life, patients may experience 'existential suffering', such as when they feel their life lacks meaning and purpose, is not worth living anymore, or they have trouble attaining peace of mind [3]. Psychological and existential forms of suffering may be addressed by using disengagement-related control strategies such as reinterpreting one's life and rescaling one's current goals.

\section{An Action-Phase Model of Control in the Disablement Process: Choosing, Holding, and Adjusting Lines of Defense}

The challenges associated with the processes of progressive chronic disease and disability require individuals to regulate their control strategies in order to realize optimal control capacity while adjusting to the pressing constraints of physical and functional losses. How can an individual affected by aging and disease-related losses adjust goals of physical wellness and functioning to the realities of biological aging and disease, but not give up altogether?

Our model suggests that the critical challenge is to hold the line of functioning where it is defensible, and adjust it where it cannot be held any more. This idea is the cornerstone of the Lines-of-Defense Model of Physical Functioning (table 1) [16]. During the onset and increase in severity of disease and compromised physical functioning, individuals have to engage with health-related goals to counteract disease and functioning loss. However, as the disease process further progresses, a given goal of maintaining functioning (e.g. get your own groceries) may become increasingly difficult to achieve on most days. While experiencing such difficulties, the individual may become uncertain about their future functional abilities and engage in testing their own capacity or in denying decline. This phase of uncertainty about whether a given goal of functioning can still be main- 
tained may extend over a substantial period of time (days to months) depending on how difficult and ambiguous it is to assess one's current capacity and likely future changes. This transitional phase of adjustment choice is similar in motivational self-regulation to the preengagement phase of optimization (see also [15] for a two-phase model of health-related goal-setting and action, HAPA). Ideally, the person should be unbiased and open to information to reach the most appropriate decision about which level of functioning to defend and what to give up. Once the individual has adjusted a goal to a lower level, she or he should become firmly engaged with the new functioning goal.

At each line of defense, the individual has to invest the available behavioral and motivational resources needed to counteract the ongoing physical decline and maintain the current level of functioning. Holding a line of defense may require increased effort and social support as the illness progresses. If it is no longer possible to hold the current line of defense, the most adaptive retreat would be one that is 'organized' in a sense that switching to the next lower level within a particular functional domain, for example, happens in an organized self-regulatory decision that involves a decision phase during which different levels are tried out mentally and in practice, and then an engagement phase during which the individual sticks to defending the new level of functioning without becoming hung up on previously lost levels of functioning.

The firm commitment to a line of defense is an invaluable safeguard, especially when the individual encounters day-to-day fluctuations in functioning. Just because there may be occasions when a given function is not working (e.g. ambulating around the home), this does not mean that an individual should give up on maintaining this function altogether. Instead, it should be recaptured as soon as the individual feels more energetic and physically capable. It is not until the failure to function at a certain level of functioning becomes predominant, that a disengagement from that line of defense should be considered and effort should be withdrawn from holding that line. Ideally, individuals and their family caregivers and health professionals would jointly switch in their commitment from one goal level to the next lower line of defense. However, switches between lines of defense may not always be well coordinated, which could lead to interpersonal conflicts and emotional distress [26].

Table 1 illustrates the Lines-of-Defense Model for motivational regulation with a progressive disease. The four major rows of the model identify four broad lines of defense regarding one's 'disease status', descending across

Lines-of-Defense Model for Managing Health Threats the rows from being 'disease free' to 'subclinical disease', 'chronic disease', and finally 'terminal illness'.

Each line of defense is associated with a 'health goal' of maintaining the current level of functioning (e.g. people with subclinical disease should be engaged with avoiding chronic disease; see second column). The third column shows the 'functioning goals' associated with each disease status. Within each level of disease status there may be multiple functioning goals, particularly within the health status of 'disability'. When considering the goals of functioning, particularly once the disease status of chronic disease is reached, the third column shows several levels that predominantly address ways of maintaining functioning in I/ADL.

The fourth column shows whether and in which sequence goal engagement, goal disengagement, and goal reengagement are involved in the respective lines of defense. In most cases, switching to a new line of defense involves disengagement from the previous (and more advanced) line and then reengaging with the new line of defense. Note that we use only a few select empirical examples in the following discussion of lines of defense. The whole range of research about how people cope with disabling progressive diseases would be too vast to cover in this article.

\section{1st Line of Defense: Maintain Disease-Free Status}

At this line of defense, the individual is focused on the ideal of disease-free physical functioning and uncompromised activities. The goal is to avoid the development of any physical dysregulation or disease. This goal is best achieved by goal engagement processes associated with general preventative health behaviors, such as eating a healthy diet, exercising regularly, and avoiding substance abuse such as smoking and excessive alcohol consumption. However, the successful use of these strategies requires substantial self-regulation efforts to withstand temptations of unhealthy foods and other nonoptimal substances [27], and to overcome the self-regulatory obstacles that could prevent engagement in regular effortful exercise.

\section{2nd Line of Defense: Avoid Chronic Disease}

At the second major line of defense, the individual has already developed a subclinical level of disease, but has an opportunity to revert to a disease-free state, or at least prevent or slow down the development of manifest and chronic disease. Acknowledging that one has acquired a subclinical level of disease is critical for the individual to focus on preventing further decline towards chronic disease. Such subclinical health problems can manifest themselves in the presence of acute physical symptoms, 
such as pain or difficulty breathing. Here, the individual has to refocus goal engagement from striving to be disease free to striving to recover or prevent a chronification of the disease. The use of specific strategies should be similar to the first line of defense in many ways. However, because the individual is aware of an emerging health problem, these strategies also include seeking medical help and adhering to treatment regimes. More generally, these types of strategies have been referred to as 'health engagement control strategies' and are aimed at maintaining and improving physical functioning [28]. Research has supported the adaptive value of using these control strategies for this line of defense by demonstrating that individuals who suffer from acute physical symptoms (but not chronic disease) can prevent depressive symptoms, cortisol dysregulation, chronic disease, and functional limitations $[29,30]$, and even expand their longevity [31] if they engage in health-related goal engagement.

\section{3rd Line of Defense: Maintain Functioning in}

Everyday Activities

This line of defense becomes predominant when the manifestation of chronic disease is no longer avoidable, and the individual needs to focus on maintaining functioning in I/ADL. The MLD predicts and abundant empirical research has shown that people abhor restrictions to activities and respond with negative affect or even depressive symptoms when such restrictions are uncontrollable [20-23]. We can thus expect that individuals will invest much effort into protecting themselves against restrictions in everyday activities.

Performing everyday activities, however, is not an allor-nothing affair. As chronic disease progresses, everyday functioning might become increasingly difficult unless individuals use medical or technical tools. For example, with progressing osteoarthritis in the knees, a person might still be able to take her/his usual walks if she or he uses anti-inflammatory pain medication. Using pain medication is inconspicuous, as compared to using a cane, walker, or even a wheelchair. Such technical aids may allow someone to keep up cherished activities, but at the same time they may be delayed as long as possible to avoid showing one's disability.

\section{3a: Regain or Maintain Lost Functional Abilities:}

Maintain Independence in I/ADL

When protecting I/ADL functioning, the individual will likely first invest time and effort to focus on performing the activities without any assistive devices or help from others (table 1, level 3a). 3b: Maintain Independence through the Use of Technical Tools or Environmental Modification

As a next step of adaptation, a person facing functional impairments might modify her/his home environment and use technical devices or medication. Consistent with this argument, research shows that among visually impaired older adults the use of assistive devices is facilitated by individuals' goal engagement-related control strategies [32]. Research on the home environment and its fit with the functional needs of disabled individuals has also shown that adapted home environments enhance functional abilities [33]. Moreover, Verbrugge and Sevak [34] studied the use and efficacy of 'personal and equipment assistance' for maintaining ADL in the context of a very large national health survey with more than 100,000 participants. Among those reporting at least some disability with basic activities such as bathing, dressing, and eating, more than $80 \%$ used some assistance. Using technical devices to maintain one's capacity to perform important I/ $\mathrm{ADL}$ is probably psychologically less burdensome than having to ask for and rely on help from other people.

\section{3c: Accept Help}

Once assistive devices and home modification become insufficient to maintain one's everyday activities, the individual may take the next step and seek out help from others. In general, chronic illnesses in old age often render individuals dependent on their spouses or children as caregivers (see [35] for a comprehensive review of dyadic coping in couples). Many people dread this dependency and burdening of kin [36] as they imagine their own future development [37].

Applying the Lines-of-Defense Model to dyadic coping with disability and illness leads to the prediction that the quality of dyadic coping depends on the degree of agreement between the patient and the caregiver about which is the appropriate line of defense at a given time (i.e. when to hold the line and when to retreat behind the next level). Being in agreement about these decisive issues of regulation should be key to optimizing both the objective and subjective effectiveness and harmony of caregiver-patient dyads. Unfortunately, available evidence suggests that caregivers' and patients' perceptions of patient functionality are typically moderately discordant - patients perceive generally higher levels of functioning than their caregivers [38].

\section{3d: Focus on Important I/ADL}

As disease and functional constraints increase, individuals will start making choices concerning their I/ADL particularly with regard to whether they attempt them 
self-reliantly or allow others to help in order to free up vitality resources to engage with the most cherished activities. Margaret Baltes [25] conceptualized this 'self-induced dependency' as an adaptive strategy aimed at securing independence for a select set of personally meaningful activities, while others are being abandoned or handed over to a caregiver's assistance. More generally, research has addressed illness and disability-based disengagement from activities in irreversibly injured or chronically ill patients. For example, when asked about the key components of a high-quality life, men with spinal cord injuries reported giving higher priority than noninjured men to activities that did not involve physical fitness and mobility [39]. Among arthritis patients, $88 \%$ gave up some activities, with $48 \%$ abandoning the activity without replacement and $40 \%$ becoming active in some replacement activities [40]. Overall, the findings on behavioral disengagement indicate that most adults are able to adapt their ADL to health-related activity restrictions, and many, especially when supported by others, manage to replace the lost activities. However, we know very little about such patients' psychological disengagement from these activities and their ability to avoid associated depressive symptoms.

\section{3e: Minimize Physical Suffering}

Physical suffering in the form of dry mouth, fatigue, pain, difficulty breathing, or nausea is a common feature of chronic illness and disability. Symptoms of physical suffering are often markers or consequences of illness and causes of disability. Thus, maintaining or regaining I/ ADL functioning requires that individuals control their physical suffering. This can be achieved through medications, changing behaviors such as sleep patterns, physical therapy, and psychological therapeutic interventions aimed at minimizing or controlling physical suffering. Because the experience of suffering is difficult to ignore and often has profound effects on everyday functioning, controlling suffering is often a prerequisite to maintaining or regaining functioning.

\section{4th Line of Defense: End of Life}

The final line of defense is one that focuses on maintaining psychological well-being while letting go of gainrelated health goals and goals of everyday functioning. The last vestige of primary control striving is focused on minimizing physical and psychological suffering, coming to terms with the end of life, minimizing burden on others, and shaping the legacy one leaves behind. Achieving these goals is extremely challenging, as it requires the in-

Lines-of-Defense Model for Managing Health Threats dividual to let go of primary control striving in those life domains that are most dear to humans and have been the central focus of control striving throughout the individual's life. Without giving up on goals such as good health and physical functioning, individuals cannot effectively pursue control over physical symptoms and minimize their own suffering as well as the suffering of family and friends, come to terms with the end of life by finding meaning in what they have accomplished in life, say goodbye to family and friends, and overall achieve a 'good' death. In short, the challenge an individual faces in the terminal phase of life is to disengage from the life and control striving that has been central throughout her/his existence, and concentrate on regulating those few remaining domains available to them, knowing that all control striving will cease in the near future. Not surprisingly, many individuals do not master this challenge well and either fail to disengage or relinquish all meaningful control striving, thus exposing themselves to substantial losses in psychological well-being during the terminal phase of their life [41].

\section{Conclusion and Future Research}

Older individuals who experience progressive disease and disability need to adapt to continuously declining levels of functioning in a way that allows them to engage with attainable goals throughout the process. We propose a model of organized goal engagement and disengagement across multiple lines of defense that is based on the MLD. This view suggests that individuals engage in control striving for optimal levels of functioning in distinctly organized cycles of goal engagement and disengagement. For levels of disease advancing from 'disease free' to 'subclinical disease', 'chronic disease', and 'terminal illness', we identify goals for primary control striving regarding health and functioning. Adjustment from one level to the next involves goal disengagement and reengagement using compensatory secondary control strategies, whereas within levels of defense, one can also benefit from using primary control strategies aimed at maintaining or improving functioning. Particularly important issues to negotiate in this process of adaptation are the questions of independence and allowing and recruiting others to help with functional disability, as well as selecting specific areas of function for which help is accepted and others where independence and general functioning is cherished and defended most. Towards the end of life, the attainment of health goals may become impossible and func- 
tioning goals may focus on psychological and existential well-being as well as on minimizing suffering.

People differ in the degree to which they can adequately self-regulate and navigate these transitions across receding lines of defense. As a consequence, individual differences in the adjustment of control strategies can determine their mental and physical health. Individual differences in the capacity to regulate one's control striving in accordance with control opportunities should play an important role in predicting outcomes in disability processes. We know very little about these individual differences in self-regulation because research so far has focused on overall levels of control perception instead of the fine-grained calibration of control-striving goals to available control capacity. Numerous studies show that psychosocial factors and particularly perceptions of being in control and exerting mastery moderate the progression within the disability process. For example, in a Swedish study of adults in advanced old age (over 86 years), perceived control and mastery predicted less increase of disability in a four-year period [42]. Further research showed that among American (but not British) elderly, strong personal control beliefs were associated with less decline in physical functioning (gait speed) and less compromised daily activities [43]. These findings are consistent with our model as global perceptions of control can be expected to fuel adaptive goal engagement efforts.

Another important individual difference may concern the manner in which a person deals with experiencing difficulties in maintaining a current goal for functioning. Some people may try to probe their own capacity and future potential by pushing themselves to the limits, whereas others may respond with denying encroaching capacity limita- tions and avoid putting their capacity to the test. Different people also may vary in the extent to which they consider their current and future goals for functioning consciously or rely on forms of preconscious processing (e.g. of failure information). In this regard, the nonconscious and automatic adjustment of goals could be particularly useful if the intentional abandonment of an unfeasible health goal would threaten a person's overall sense of identity.

Descriptive and process-oriented research on such differences is likely to inform intervention programs by uncovering adaptive patterns of self-regulation. Moreover, people function in relationships, which often involve spousal or other family caregivers. These social partners may be more or less in sync with regard to the line of defense the patient has selected at a given point in time to hold onto. Instructing caregivers and patients to choose and adapt their line of defense in a coordinated way will be an important contribution to optimize both physical and psychological functioning in families dealing with disease and disability.

Finally, the Lines-of-Defense Model can also be applied to the inverse process, i.e. rehabilitation from severely restricted to more or less fully restored functioning. We expect that people engaged in rehabilitation after surgery, injury, or a successfully treated disease can recover functioning by progressing in a stepwise manner from one line of advancement to the next. Moving forward is not a given and the challenge is to adapt one's goal-setting to possibly improving levels of health and functioning. Again, the social network partners of a recovering individual may play an important role in either impeding or promoting the individual's progress across lines of advancement to full recovery.

\section{References}

1 Halter J, et al: Hazzard's Geriatric Medicine and Gerontology, ed 6. New York, McGraw Hill, 2009.

2 Heckhausen J, Schulz R: A life-span theory of control. Psychol Rev 1995;102:284-304.

3 Heckhausen J, Wrosch C, Schulz R: A motivational theory of life-span development. Psychol Rev 2010;117:32-60.

4 Schulz R, Heckhausen J: A life-span model of successful aging. Am Psychol 1996;51:702714.

5 Brandtstädter J: Goal pursuit and goal adjustment: Self-regulation and intentional self-development in changing developmental contexts. Adv Life Course Res 2009;14:52-62.

6 Freund AM, Baltes PB: Selection, optimization, and compensation as strategies of life management: correlations with subjective indicators of successful aging. Psychol Aging 1998; 13:531-543.

7 Haase C, Heckhausen J, Wrosch C: Developmental regulation across the life span: towards a new synthesis. Dev Psychol 2013;49:964-972.

8 Poulin M, Haase CM, Heckhausen J: Engagement with and disengagement from goals across the life span: a comparison of two-process models of developmental regulation; in Greve W, Rothermund K, Wentura D (eds): The Adaptive Self: Personal Continuity and Intentional Self-Development. Göttingen, Hogrefe/Huber Publishers, 2005, pp 117135.

-9 Heckhausen H, Gollwitzer V: Thought contents and cognitive functioning in motiva- tional and volitional states of mind. Motiv Emot 1987;11:101-120.

10 Heckhausen J, Wrosch C, Fleeson W: Developmental regulation before and after a developmental deadline: the sample case of 'biological clock' for child-bearing. Psychol Aging 2001;16:400-413.

11 Carver CS, Scheier MF: On the Self-Regulation of Behavior. New York, Cambridge University Press, 1998.

12 Brandtstädter J: Emotion, cognition, and control: limits of intentionality; in Perrig WJ, Grob A (eds): Control of Human Behavior, Mental Processes, and Consciousness: Essays in Honor of the 60th Birthday of August Flammer. Mahwah, Lawrence Erlbaum Associates, 2000, pp 3-16. 
13 Schulz R, Heckhausen J, O'Brien AT: Control and the disablement process in the elderly. J Soc Behav Pers 1994;9:139-152.

-14 Sprangers MAG, Schwartz CE: Integrating response shift into health-related quality of life research: a theoretical model. Soc Sci Med 1999;48:1507-1515.

15 Schwarzer R, Lippke S, Luszczynska A: Mechanisms of health behavior change in persons with chronic illness or disability: the health action process approach (HAPA). Rehabil Psychol 2011;56:161-170.

16 Heckhausen J: The life-span theory of control as a paradigm to study illness and disability in old age. UC/APA Conference on Health Psychology and Aging, Lake Arrowhead, 2003.

17 Boerner K, et al: Tackling vision-related disability in old age: an application of the lifespan theory of control to narrative data. J Gerontol B Psychol Sci Soc Sci 2010;65:2231.

18 Verbrugge LM, Jette AM: The disablement process. Soc Sci Med 1994;38:1-14.

19 Field MJ, Jette AM (eds): The Future of Disability in America. Washington, National Academies Press, 2007.

20 Bookwala J, Lawson B: Poor vision, functioning, and depressive symptoms: a test of the activity restriction model. Gerontologist 2011;51:798-808.

21 Williamson GM, Christie J: Aging well in the 21st century: challenges and opportunities; in Lopez SJ, Snyder CR (eds): Oxford Handbook of Positive Psychology. New York, Oxford University Press, 2009, pp 165-169.

22 Williamson GM, Shaffer DR: The activity restriction model of depressed affect: antecedents and consequences of restricted normal activities; in Williamson GM, Shaffer DR, Parmelee PA: Physical Illness and Depression in Older Adults: A Handbook of Theory, Research, and Practice. New York, Plenum, 2000, pp 173-200.
23 Williamson GM, Shaffer DR, Schulz R: Activity restriction and prior relationship history as contributors to mental health outcomes among middle-aged and older spousal caregivers. Health Psychol 1998; 17: 152-162.

24 Martire LM, Stephens MAP, Schulz R: Independence centrality as a moderator of the effects of spousal support on patient well-being and physical functioning. Health Psychol 2011;30:651-655.

25 Baltes MM: Dependencies in old age: gains and losses. Curr Dir Psychol Sci 1995;4:1419.

26 Schulz R, et al: Magnitude and causes of bias among family caregivers rating Alzheimer disease patients. Am J Geriatr Psychiatry 2013;21:14-25

27 Vohs KD, Hetherton TF: Self-regulation failure: a resource depletion approach. Psychol Sci 2000;11:249-254.

28 Wrosch C, Schulz R, Heckhausen J: Health stresses and depressive symptomatology in the elderly: the importance of health engagement control strategies. Health Psychol 2002; 21:340-348

29 Wrosch C, et al: Physical health problems: depressive modem and cortisol secretion in old age: buffer effects of health engagement control strategies. Health Psychol 2007;26:341349.

30 Wrosch C, Schulz R: Health engagement control strategies and 2-year changes in older adults' physical health. Psychol Sci 2008;19: 537-541.

31 Hall NC, et al: Control striving in older adults with serious health problems: a 9-year longitudinal study of survival, health, and well-being. Psychol Aging 2010;25:432-445.

32 Becker S, Wahl H-W, Schilling O: Assistive device use in visually impaired older adults: role of control beliefs. Gerontologist 2005;45: 739-746.

33 Wahl HW, et al: The home environment and disability-related outcomes in aging individuals: what is the empirical evidence? Gerontologist 2009;49:355-367.
34 Verbrugge LM, Sevak P: Use, type, and efficacy of assistance for disability. J Gerontol B Psychol Sci Soc Sci 2002;57:366-379.

-35 Berg CA, Upchurch R: A developmental-contextual model of couples coping with chronic illness across the adult life span. Psychol Bull 2007;133:920-954.

36 McPherson CJ, Wilson KG, Murray MA: Feeling like a burden to others: a systematic review focusing on the end of life. Palliat Med 2007;21:117-128.

37 Frazier LD, Cotrell V, Hooker K: Possible selves and illness: a comparison of individuals with Parkinson's disease, early-stage $\mathrm{Al}$ zheimer's disease, and healthy older adults. Int J Behav Dev 2003;27:1-11.

38 Magaziner J, et al: Proxy reporting in five areas of functional status: comparisons with self-reports and observations of performance. Am J Epidemiol 1997;146:418-428.

39 Weitzenkamp DA, et al: Ranking the criteria for assessing quality of life after disability: evidence for priority shifting among long-term spinal cord injury survivors. Br J Health Psychol 2000;5:57-69.

40 Zimmer Z, Hickey T, Searle MS: The pattern of change in leisure activity behavior among older adults with arthritis. Gerontologist 1997;37:384-392.

41 Gerstorf D, et al: Late-life decline in well-being across adulthood in Germany, the United Kingdom, and the United States: something is seriously wrong at the end of life. Psychol Aging 2010;25:477-485.

42 Fauth EB, et al: Physical, cognitive, and psychosocial variables from the Disablement Process Model predict patterns of change in disability for the oldest-old. Gerontologist 2007;47:613-624.

43 Clarke P, Smith J: Aging in a cultural context: cross-national differences in disability and the moderating role of personal control among older adults in the United States and England. J Gerontol B Psychol Sci Soc Sci 2011;66:457-467. 